\title{
The Influence of Working Environment on the Performance and Productivity of the Workers Belongs to Various Sectors of Islamabad: A Statistical Survey
}

\author{
Sadia Sadiq \\ Research Scholar PhD-Education, International Islamic University, RWP
}

\begin{abstract}
A work environment can be identified as the place that one works, which means the milieus around a person. It is the social and professional environment in which a person is supposed to interact with a number of people. The work environment has a significant impact upon employee performance and productivity. This study aims to provide the vital information regarding the work environment factors which have an influence on employee performance. The work place becomes an integral part of the work itself. Businesses must step outside their traditional roles to create a work environment where employees enjoy what they do, have pride in what they do, can reach their potential. The respondents surveyed were the employees of the various government and private sectors of District Islamabad. Total number of employees surveyed was 100. The study showed how the work environment in these organizations is affecting the employee performance. Objectives of the study were to ascertain the relationship between employees and their working environment, to determine the impact of work environment on employee performance and to suggest measures and make appropriate recommendations to improve the working conditions for better performance. Descriptive sample survey used to carry out the study. Simple random sampling technique was respectively used to select the respondents for the study and data was analyzed and interpreted by using the mean, standard deviation and chi-square through SPSS.
\end{abstract}

Keywords: Work Environment, Employee Performance, Participative Management, Productivity, Interpersonal Relationship, Training and Development, Employee Welfare, Monetary Benefits, Supervision, Advancement.

DOI: $10.7176 / \mathrm{JRDM} / 60-02$

Publication date:October $31^{\text {st }} 2019$

\section{INTRODUCTION}

A work environment can be identified as the place that one works, which means the milieus around a person. It is the social and professional environment in which a person is supposed to interact with a number of people. The work environment has a significant impact upon employee performance and productivity. By work environment we mean those processes, systems, structures, tools or conditions in the workplace that impact favorably or unfavorably individual performance. The work environment also includes policies, rules, culture, resources, working relationships, work location, and internal and external environmental factors, all of which influence the ways those employees perform their job functions.

It is the quality of the employee's workplace environment that most impacts on the level of employee's motivation and subsequent performance. How well they engage with the organization, especially with their immediate environment, influences to a great extent their error rate, level of innovation and collaboration with other employees, absenteeism and, ultimately, how long they stay in the job.The environment that people are required to work in can have a significant impact on their ability to undertake the tasks that they have been asked to do. This can affect productivity and employee health and well-being. The key factors fall into two categories, those that are driven by procedures, protocols and management requirements and the factors that arise from premises, office or factory design. Management driven factors include the development of Organization plans such as the allocation of responsibilities at all levels of the organization, definition of job descriptions and the degree of access to the management and administrative support needed to complete their tasks; Working patterns, shiftworking, break times, absence or holiday cover; and Health and safety policies, including the provision of training, development of safe working practices and the adequate supply of protective clothing and equipment. In today's competitive business environment, management cannot afford to waste the potential of their workforce. The key factors in work place environment impact greatly on employee's level of motivation and their performance. The workplace environment set in place impacts employee morale, productivity and performance- both positive and negative. And if the circumstances are not good it will be affecting the performance of the employees in the form of delay in work completion, frustration, affect on personal growth etc.

In an effort to motivate employees, organizations have implemented performance based pay, practices to help balance both work and family and various forms of information sharing.The Organizations today consider employees as their top most priority. A lot of effort is put in order to attain, retain and motivate them. The traditional role of employees is no more effective and the organizations are finding new ways of working. The key to organizational success is the competitive workforce (Luthans and Stajkovic, 1999; Pfeffer, 1994). The 
organizations strive hard to align organizational strategies and objectives with employee's behaviors in order to stay competitive (Boxall and Purcell, 2003; Warech and Tracey, 2004). The way in which employees accomplish organizationally set goals and relate their interpersonal behaviors to the organizational norms can be termed as employee performance (Keller, 2006)

\section{STATEMENT OF THE PROBLEM}

The work environment has a significant impact upon employee performance and productivity. Work environment means those processes, systems, structures, tools or conditions in the workplace that impact favorably or unfavorably individual performance. The work environment also includes policies, rules, culture, resources, working relationships, work location, and internal and external environmental factors, all of which influence the ways that employee perform their job functions.

It is widely accepted that the work environment has an impact - positive or negative - on employee performance. The work environment strongly influences the extent to which employees are engaged in their work and committed to the organization. The work environment strongly influences the extent to which employees are engaged in their work and committed to the organization. Disengaged workers produce mediocre results; highly engaged workers produce extraordinary results. So it is necessary to study the impact of the work environment in organizations on the performance of their employees.

\section{RESEARCH QUESTIONS}

- What is the relationship between the employee's performance and their working environment?

- How does the working environment affect employee's productivity/performance?

- Which measures can be put in place to improve the working conditions of employees for better performance?

\section{OBJECTIVES OF THE STUDY}

- The main objective of this study is to find out how the workplace environment affects employee's performance, welfare and productivity.

- The specific objectives are;

- To ascertain the relationship between employees and their working environment.

- $\quad$ To determine the impact of work environment on employee performance.

- To suggest measures and make appropriate recommendations to improve the working conditions for better performance?

\section{Literature Review}

Chapin(1995) stated that the environment is man's immediate surrounding which he manipulates for his existence. Wrongful manipulation introduces hazards that make the environments unsafe and impede the productivity rate of the worker. A large number of work environment studies have shown that workers/users are satisfied with reference to specific workspace features. Therefore, the workplace entails an environment in which the worker performs his work.

Mike (2010), Shikdar (2002) studied that an effective workplace is an environment where results can be achieved as expected by management. Physical environment affect how employees in an organization interact, perform tasks, and are led. Physical environment as an aspect of the work environment have directly affected the human sense and subtly changed interpersonal interactions and thus productivity. This is so because the characteristics of a room or a place of meeting for a group have consequences regarding productivity and satisfaction level.

The workplace environment is the most critical factor in keeping an employee satisfied in today's business world. Today's workplace is different, diverse, and constantly changing. The typical employer/employee relationship of old has been turned upside down. Workers are living in a growing economy and have almost limitless job opportunities.

Smith (2011) viewed that this combination of factors has created an environment where the business needs its employees more than the employees need the business. A large number of work environment studies have shown that workers/users are satisfied with reference to specific workspace features.

Becker (1981); Humphries (2005); Vetch, Charles, New sham, Marquardt \& Greets (2004); Karasek \& Theorell (1990)Examined that these features preference by users are highly significant to their productivity and workspace satisfaction, they are lighting, ventilation rates, access to natural light and acoustic environment.

Delanie (2004); Milton, Glen cross \& Walters, 2000; Vetch \& New sham (2000) studied that Lighting and other factors like ergomic furniture has been found to have positive influence on employees health and consequently on productivity. This is so because light has a profound impact on worker's/people's physical, 
physiological and psychological health, and on their overall performance at the workplace.

Larsen, Adams, Deal, Kwan \& Tyler (1998); Vetch \& Gifford (1996)conclude that ambient features in office environments, such as lighting, temperature, existence of windows, free air movement etc, suggest that these elements of the physical environment influence employee's attitudes, behaviors, satisfaction, performance and productivity. Closed office floor plan, whether each employee has a separate office of their own or there are a few people in each closed office, allows staff a greater amount of privacy than an open plan office layout.

They have the chance to work in peace and quiet, keeping them focused on the tasks in hand without getting overtly distracted by what their colleagues are doing. Mwbex, (2010) said that It offers employees a thinking fame or be creative without much interruption .Evans \& Johnson (2000) concluded that in the open office plan, noise existence is stressful and demotivating, posses' high level of distraction and disturbance coupled with low privacy level. Noise is one of the leading causes of employees' distraction, leading to reduced productivity, serious inaccuracies, and increased job-related stress. According to Bruce (2008) study showed that workplace distractions cut employee productivity by as much as $40 \%$, and increase errors by $27 \%$. Maloney (2011) citing Loftiness study of 2003 confirmed the importance of natural light and air (ventilation) to worker productivity. The study showed a 3-18\% gain in productivity in buildings with day-lighting system. The finding showed that the absence of noise increased worker's productivity due to less distractions and reduction in job-related stress.

It is line with Bruce (2008) finding that reduction in workplace noise reduces physical symptoms of stress by as much as $27 \%$ and performance of data-entry workers increased with a $10 \%$ improvement in accuracy. Similarly, good ventilation and room temperature increased productivity and reduces stress in workers.

Maloney (2012) confirmed this when it was established that controllability of system for thermal comfort and lighting improved productivity of workers between 0.2 and 3 percent. Another finding from the study revealed that communication plays a key role in the success of any workplace program and practices. This is in line with the view of Taylerson (2012) who confirm that effective workplace communication helps organizations select and tailor their Programs and policies to meet the specific needs of their employees. By meeting the needs of employees, their morale are boosted, they are psychologically and emotionally stable to perform effectively and efficiently at workplace thereby increasing the productivity of the organization.

Good communication network helps to develop better rapport among employees which consequently make them to be happier and more successful in their roles at the workplace. The improved morale in turn makes the employees to remain loyal to organization. This is in consonance with Dunne (2011) that, effective communication makes employees more informed and naturally more trusting of their colleagues and surer that any dependent work is being done. This position is making the organization to be assertive of their survival and the employees' wellbeing.

\section{Materials and Methods}

A research design is a conceptual structure within which the research would be conducted. The study adopts the descriptive survey research design to investigate the influence of workplace environment (workspace and communication) on workers welfare, performance and productivity. The Multiple Regression technique will be used to analyze the data. The major purpose of the descriptive research is description of the state of affairs as it exists; usually includes surveys and fact-finding enquiries. The populations for the study are employees of various sectors of government and private departments in District Islamabad. Sampling is that part of statistical practice concerned with the selection of an unbiased or random subset of individual observations within a population of individuals intended to yield some knowledge about the population of concern. The sampling technique used here is Random sampling.

A purposive cluster sample of one hundred employees will be selected. The ages of the respondents will range between 18 and 55 years. They were both male and female. Their academic attainment was range from Secondary School Certificate to Higher Education. Collection of information is called as data. Data is of two types. Primary data are those which are collected afresh and for the first time, and thus happen to be original in character. The questionnaire was found to be the suitable research instrument to collect the primary data from the employees. The collected data was checked for consistency and then frequencies and percentages were used to show responses of the demographical distribution. The software use for the analysis of the findings is SPSS (Statistical Package for Social Sciences).

\section{Variables for the study}

A concept which can take different quantitative values is called variable. It can be quantitative or qualitative.

\section{i. Dependent Variable}

A dependent variable is a variable that depends or is a consequence of another variable. In this research the dependent variables are employee performance and productivity.

\section{ii. Independent Variable}

The independent variables were analyzed based on how it affects the performance and productivity of worker. . In 
this research the independent variables was working environment.

\section{Demographical Data Analysis}

\begin{tabular}{|l|r|r|}
\hline Employee's age \\
\hline $18-24$ & Frequency & Percent \\
$25-30$ & 16 & 10.6 \\
$31-40$ & 44 & 36.8 \\
$40>$ & 19 & 17.4 \\
Total & 21 & 35.2 \\
\hline
\end{tabular}

Position
\begin{tabular}{|l|r|r|}
\hline & Frequency & Percent \\
\hline clerical & 2 & 4.4 \\
Low & 42 & 8.4 \\
Middle & 37 & 67.4 \\
top & 17 & 19.8 \\
Total & 100 & 100.0 \\
\hline
\end{tabular}

Employee's gender

\begin{tabular}{|l|r|r|}
\hline & Frequency & Percent \\
\hline male & 67 & 67.0 \\
female & 33 & 33.0 \\
Total & 100 & 100.0 \\
\hline
\end{tabular}

Sector
\begin{tabular}{|l|r|r|}
\hline & Frequency & Percent \\
\hline education & 47 & 43.4 \\
trading & 35 & 13.0 \\
construction & 12 & 4.0 \\
other & 6 & 39.6 \\
Total & 100 & 100.0 \\
\hline
\end{tabular}

Employee's marital status
\begin{tabular}{|l|r|r|}
\hline & Frequency & Percent \\
\hline single & 59 & 59.0 \\
married & 41 & 41.0 \\
Total & 100 & 100.0 \\
\hline
\end{tabular}

Monthly income

\begin{tabular}{|l|r|r|}
\hline & Frequency & Percent \\
\hline$<5000$ & 9 & 1.8 \\
$5000-15000$ & 22 & 22.0 \\
$16000-25000$ & 27 & 33.4 \\
$26000-35000$ & 11 & 20.2 \\
$36000-45000$ & 16 & 11.2 \\
$46000-55000$ & 8 & 5.6 \\
$56000-65000$ & 2 & 4.0 \\
$66000-75000$ & 3 & .4 \\
$75000>$ & 2 & 1.4 \\
Total & 100 & 100.0 \\
\hline
\end{tabular}

\section{Hypothesis 1:}

$H_{\circ}$ : There is no association between worker's performance and regularly arranged staff meetings $\mathrm{H}_{1}$ : There is association between worker's performance and regularly arranged staff meetings Level of significance:

$\alpha=0.05$

Test statistics to be used:

Calculations:

$$
\chi^{2}=\sum_{i=1}^{500} \frac{\left(o_{i}-e_{i}\right)^{2}}{e_{i}}
$$


Chi-Square Tests

\begin{tabular}{|l|l|l|l|}
\hline & Value & df & Asymp \\
\hline Pearson Chi-Square & $14.970 \mathrm{a}$ & 20 & .778 \\
Likelihood Ratio & 19.246 & 20 & .506 \\
Linear-by-Linear & .160 & 1 & .689 \\
Association & 100 & & \\
N of Valid Cases & 100 \\
\hline
\end{tabular}

Critical region:

If $\mathrm{p}$-value $>0.05$ then accept $\mathrm{H}$ 。

If $\mathrm{p}$-value $<0.05$ then reject $\mathrm{H}$ 。

Conclusion:

As shown in table, chi-square test of independence resulted in a p-value of 0.778 . Since the p-value is greater than 0.05 , the study data accept the hypothesis, so we concluded that the employee's performance and regularly arranged staff meetings appear to be independent

Hypothesis 2:

H。: There is no association between worker's performance and department's poor orientation

$\mathrm{H}_{1}$ : There is association between worker's performance and department's poor orientation

Calculation:

Chi-Square Tests

\begin{tabular}{|l|l|l|l|}
\hline & Value & df & Asymp \\
\hline $\begin{array}{l}\text { Pearson Chi- } 18.561 \mathrm{a} \\
\text { Square } \\
\text { Likelihood Ratio } \\
\begin{array}{l}\text { Linear-by-Linear } \\
\text { Association } \\
\text { N of Valid Cases }\end{array}\end{array} 1052$ & 20 & 20 & .550 \\
& 100 & 1 & .517 \\
\hline
\end{tabular}

Conclusion:

As shown in table, chi-square test of independence resulted in a p-value of

0.550. Since the p-value is greater than 0.05 , the study data accept the hypothesis, so we concluded that the employee's performance and department's poor orientation appear to be independent.

Hypothesis 3:

$\mathrm{H}_{\circ}$ : There is no association between worker's performance and his goal

$\mathrm{H}_{1}$ : There is association between worker's performance and his goal

Calculation:

Chi-Square Tests

\begin{tabular}{|l|l|l|l|}
\hline & Value & df & Asymp. \\
\hline Pearson Chi-Square & $13.788 \mathrm{a}$ & 20 & .841 \\
Likelihood Ratio & 16.925 & 20 & .658 \\
Linear-by-Linear & .514 & 1 & .473 \\
Association & 100 & & \\
N of Valid Cases & 100 & & \\
\hline
\end{tabular}

Conclusion:

As shown in table, chi-square test of independence resulted in a p-value of

0.841 . Since the p-value is greater than 0.05 , the study data accept the hypothesis, so we concluded that there is no association between the employee's performance and his goal.

Hypothesis 4:

$\mathrm{H}_{\circ}$ : There is no association between worker's performance and satisfaction of salary.

$\mathrm{H}_{1}$ : There is association between worker's performance and satisfaction of salary. 
Calculation:

Chi-Square Tests

\begin{tabular}{|l|l|l|l|}
\hline & Value & df & Asymp. \\
\hline Pearson Chi-Square & $25.610 \mathrm{a}$ & 20 & .179 \\
Likelihood Ratio & 30.720 & 20 & .059 \\
Linear-by-Linear & 8.262 & 1 & .004 \\
Association & 100 & & \\
N of Valid Cases & & & \\
\hline
\end{tabular}

Conclusion:

As shown in table, chi-square test of independence resulted in a p-value of

0.179 . Since the $\mathrm{p}$-value is greater than 0.05 , the study data accept the hypothesis, so we concluded that the employee's performance and satisfaction of salary appear to be independent.

Hypothesis 5:

$\mathrm{H}_{\circ}$ : There is no association between worker's performance and effects of criticism.

$\mathrm{H}_{1}$ : There is association between worker's performance and effects of criticism.

Calculation

Chi-Square Tests

\begin{tabular}{|l|l|l|l|}
\hline & Value & df & Asymp. \\
\hline Pearson Chi-Square & $17.293 \mathrm{a}$ & 20 & .634 \\
Likelihood Ratio & 17.375 & 20 & .628 \\
Linear-by-Linear & .405 & 1 & .524 \\
Association & 100 & & \\
N of Valid Cases & 100 & \\
\hline
\end{tabular}

\section{Conclusion:}

As shown in table, chi-square test of independence resulted in a p-value of

0.634. Since the p-value is greater than 0.05 , the study data accept the hypothesis, so we concluded that the employee's performance and effects of criticism appear to be independent.

\section{Results and Discussion}

According to past researches the work environment has effect on the performance level of employees. Absence of office building, lightning, and equipment can affect the performance of the employees.

This work was try to explain how working environment influences workers performance. It is assume that working environment consists of two components that are physical environment and behavior component

Physical environment comprises the comfort level (presence of office building and working tools) which influences worker's availability, productivity and competence. Also there is an office layout (presence of privacy) which influences health workers productivity and competence. The behavior component of environment (how workers interact with each other and absence of noise) was tend to influence productivity and responsiveness, and in totality they may improve or decrease workers performance.

Past researches concluded that the respective authority should provide good working environment to its employees, so as to enable them to perform better.

\section{REFERNCES}

1. Luthans, F. and A.D. Stajkovic, 1999. Reinforce for performance: the Need to Go beyond Pay and EvenReward. pp: 49-57.

2. Pfeffer, J., 1994. Competitive Advantage through People. Boston: Harvard Business School Press.

3. Boxall, P. and J. Purcell, 2003.Strategy and Human Resource Management, Palgrave Macmillan, NY.

4. Warech, M. and Tracey, J.B. 2004.Evaluating the impact of human resources: identifying what matters. Cornell Hotel and Restaurant Administration Quarterly, 45: 376-387.

5. Keller, R.T., 2006. Transformational leadership, initiating structure and substitutes for leadership: Alongitudinal study of R and D project team performance. Journal of Applied Psychology, 91: 202-210.

6. Becker, F. (2002).Improving organisational performance by exploiting workplace flexibility. Journal of Faculty Management, 1(2), 154-162.

7. Becker, F. O. (1981).Workspace creating environments in organisation. New York: Praeger. 
8. Brennan, A., Chugh, I., \& Kline,T. (2002). Traditional versus open office design: A longitudinal field study. Environment and Behaviour, 34(3), 279-299.

9. Broadland District Council (2011), Health and safety self assessment questionnaire, Retrieved May 11, 2011 from http://www.broadland.gov.uk.

10. Bruce. (2008).How much can noise affect your worker's productivity, Retrieved February 29, 2012 from http://www.office-sound-masking.com/2008/02/29.

11. Canadian Centre for Communication (2003).Effectiveness of participative communication. Journal of Human Development, 40( 9), 422-423.

12. Challenger, J.A. (2000).24 Trends reshaping the workplace. The Futurist, 35-41.

Chandrasekar, K. (2011).Workplace environment and its impact on organisational performance in public sector organisations. International Journal of Enterprise Computing and Business Systems, 1(1) Retrieved December 20, 2011 from http://www.ijecbs.com/January2011/N4Jan2011.pdf.

13. Chapins, A. (1995). Workplace and the performance of workers. Reston: USA.

Darren, S., \& Greg, D. (2009). An infrastructure vision for the 21st century. Retrieved January 29, 2011 from http://www.nga.org.

14. Dilani, A. (2004). Design and health III: Health promotion through environmental design. Stockholm, Sweden: International Academy for Design and Health.

15. Dunne, Rod. (2011). Effective communication in the workplace. Retrieved February 27, 2012 from http://www.Improvemybusiness.com.au/managr-staff/staff development..

16. Evans, G.W., \& Johnson, D. (2000). Stress and open-office noise. Journal of Applied Psychology, 85(5), 779783.

17. Fleming, M., \& Larder, R. (1999). When is a risk not a risk. Professional Safety, 69(3), 30-38.

18. Hameed, Amina \& Amjad, Shela. (2009). Impact of office design on employees' productivity: A case study of banking organisations of Abbotttabad, Pakistan. Journal of Public Affairs, Administration and Management, 3(1), 2009. Retrieved January 18, 2012 from http://www.scientific journals.org/journals2009/articles/1460.pdf.

19. Hedge, A. (1986). Open versus enclosed workspace: The impact of design on employee reactions to their office: Behavoural issues in office design. NY: Van Nostrand Reinhold.

20. Hedge, A. (2000). Where are we in understanding the effect of where we are? Ergonomics 43(7), 1019-1029.

21. Huges, J. (2007). Office design in pivotal to employee productivity. Sandiego Source, The Daily Transcript, July, 2007.

22. Humphries, M. (2005). Quantifying occupant comfort: Are combined indices of the indoor environment practicable? Building Research and Information, 33(4), 317-325.

23. J'Istvan in Business. (2010). Human resource management and environmental effects on communication. Retrieved April 10, 2010 from http://www.bizcovering.com/business/human-resource-management-andenvironmental-effect-on-communication

24. Karasek, R., \& Theorell, T. (1990). Health work: Stress, productivity and the reconstruction of working life. New York: Basic Books.

25. Larsen, L., Adams, J., Deal, B., Kweon,B., \& Tyler, E. (1998). Plants in the workplace: The effect of plant density on productivity, attitude and perceptions. Environment and Behavior, 30(3), 261-281.

26. Makin, A.M. (2006). A new conceptual framework to improve the application of occupational health and safety management system. In proceeding of the European safety and reliability conference, 2006. Estoril, Portugal: Taylor \& Francis Publishers.

27. Mike, A. (2010). Visual workplace: How you see performance in the planet and in the office. International Journal of Financial Trade, 11(3), 250-260.

28. Milton, D.K., Glencross, P.M. \& Walters, M.D. (2000). Risk of sick leave associated with outdoor air supply rate, humidification and occupant complaints. Indoor Air. 10(4), 212-221.

29. Moloney, Claire. (2011). Workplace productivity and LEED building. Retrieved February 29, 2012 from http://www.green-building.com/content.

30. Mubex.C.M. (2010). Closed offices versus open plan layout. Retrieved April 1, 2010 from http://www.mubex.com/sme/closed-vs-open-plan-officers.htm.

31. Newfoundland and Labrador Statistics Agency (NLSA). (2008). Work environment survey 2007/2008. Public Service Secretariat, Human Resource Policy and Planning Division, Newfoundland, Labrador.

32. Quilan, M. (2001). Precarious employment: Work re-organization and the factoring of OHS management. International Journal of Systematic Occupational Health and Safety Management, 24(10), 175-178.

33. Shikdar, A.A. (2002). Identification of ergonomic issues that affect workers in oilrigs in desert environment. International Journal of Occupational Safety and Ergonomic, 10 (8), 169-177.

34. Smith, D.G. (2011). Work environment more important to employees. Retrieved November 25, 2011 from http://www.businessknowhow.com.

35. Steven, M.S. (2003). Economics: Principles in action. New York: Pearson Prentice Hall. 
36. Tayler, Beth (2012). Creating a psychologically healthy workplace: The role of communication. Retrieved February 27, 2010 from http://www.phwa.org/resources/creating a healthy workplace.

37. Terricone, P., \& Luca, I. (2002). Employees, teamwork and social interdependence: A formula for successful business? Team Performance Management: An International Journal, 8(3/4), 54-55.

38. The Gensler+Performance Index. The U.S. Workplace Survey (2006), Retrieved October 26, 2011 from www.gensler.com.

39. Uzee, J. (1999). The inclusive approach: Creating a place where people want to work. Facility Management Journal of the International Facility Management Association, 26-30.

40. Veitch, J., \& Gifford, R. (1996). Choice, perceived control and performance decrement in the physical environment. Journal of Environmental Psychology, 16, 269-276.

41. Veitch, J.A., \& Newsham, G.R. (2000). Exercised control, lighting choices and energy use: An office simulation experiment. Journal of Environmental Psychology, 20(3), 219-237.

42. Veitch, J.A., Charles, K.E., Newsham, G.R., Marquardt, C.J.G., \& Geerts, J. (2004). Workstation characteristics and environmental satisfaction in open-plan offices. COPE Field Findings (NRCC-47629) Ottawa, Canada: National Research Council.

43. Work Environment Survey (2008). Public Service Secretariat, Human Resource Policy and Planning Division, New Found land, Labrador. 